\title{
Diminishing Returns to Density and Public Transit
}

Murtaza Haider ${ }^{\star}$

Keywords: mode split, public transit, ridership, transit planning, diminishing returns, population density

https://doi.org/10.32866/10679

\section{Transport Findings}

\begin{abstract}
This article uses piecewise regression to explore diminishing returns to population density and identifies the density thresholds in the three most populous Canadian metropolitan areas beyond which any increase in population density is associated with declining marginal returns in transit mode split. An improved understanding of diminishing returns will enable planners and transit operators to focus on specific transit modes and service areas where increasing population densities are more likely to correlate with higher transit mode splits.
\end{abstract}

\section{RESEARCH QUESTION AND HYPOTHESIS}

Previous research has found a strong positive correlation between transit mode split and population density. From cross-sectional studies (Newman and Kenworthy 1991) to localized analyses of travel mode choice, studies have consistently found "higher transit use with increasing density" (Polzin, Chu, and Rey 2000). And whereas higher population or employment densities may not be enough on their own to cause higher transit mode split, they are considered enabling determinants of transit mode split along with other builtform proxies (Cervero and Kockelman 1997; Chakraborty and Mishra 2013). The very premise that built environment influences travel behavior carries a questionable "implicit conception of causality" (Næss 2015). Other critical reviews of density suggest that it "explains only a small fraction of the variation" in travel behavior (Ewing et al. 2018). Furthermore, an improvement in the quality or quantity of public transit (e.g., extending higher-order transit to suburbs) can improve the desirability of nearby parcels, contributing to accelerated land development and a subsequent increase in density (Cervero and Kang 2011).

In Toronto, an urban region with almost six million inhabitants (Statistics Canada 2017), development guidelines stipulate minimum thresholds for population densities to "make efficient use of land and infrastructure and support transit viability" (Government of Ontario 2017). Similar policy prescriptions are found in jurisdictions across the developed world.

Population density, as an input, could be subject to diminishing marginal returns. Mankiw (2014) defines diminishing returns as "the property whereby the benefit from an extra unit of an input declines as the quantity of the 
input increases." This study investigates the specific thresholds beyond which an increase in population density is correlated with a lower marginal increase in transit mode splits.

\section{METHODS AND DATA}

This study used 2016 Census data for the three most populous census metropolitan areas in Canada, namely Toronto (5.93 million), Montreal (4.09 million), and Vancouver (2.46 million). The core municipality and the neighboring suburbs form a census metropolitan area (Statistics Canada $2012 b$ ). Population density and public transit mode split for work trips were analyzed at the census tract (CT) level, which approximates a neighborhood with a population between 2,500 and 8,000 (Statistics Canada 2012a). Descriptive statistics are presented in Table 1.

The geographic size of CTs varies considerably, from vast suburban CTs spanning several square kilometers in size to tiny tracts in the urban core. This results in some tracts reporting artificially very high population densities, which is partially due to the arbitrary spatial aggregation, also known as the modifiable areal unit problem (Zhang and Kukadia 2005). This article, therefore, computes average densities such that, for each CT, the reported population density is the average density of CTs whose centroids fall within a 1 $\mathrm{km}$ radius.

The study applied piecewise (segmented) regression to determine the "knot" or the breakpoint where the relationship between density and transit mode split transforms (Mitchell 2012). The nonlinear model simultaneously estimates the breakpoint and the slopes around it.

If $y$ is the transit mode split (share of work trips made by public transit), $d$ is the population density, and $k$ is the knot, the nonlinear regression model is presented in the following equation:

$y=\left(\alpha+\beta_{1} d\right) *\left(d_{d<k}\right)+\left(\alpha+\beta_{1} k+\beta_{2} *(d-k)\right) *\left(d_{d \geq k}\right)$

Equation 1

If the estimate for slope at densities beyond the breakpoint $\left(\beta_{2}\right)$ is less than the slope before the breakpoint $\left(\beta_{1}\right)$, it is taken as evidence in support of diminishing returns to density.

\section{FINDINGS}

Using average population density as a regressor, the piecewise regressions estimated breakpoints at 7,763, 8,475, and 7,929 persons per square kilometer for Toronto, Montreal, and Vancouver, respectively (Table 2). The estimated slopes $\left(\beta_{2} s\right)$ beyond the breakpoints (knot) are smaller in magnitude than the slopes before the knots $\left(\beta_{1} s\right)$, supporting the argument that the strength of the association between population density and transit mode split weakens 


\begin{tabular}{|c|c|c|c|c|c|}
\hline Toronto & Obs. & Mean & Std. Dev. & Min & Max \\
\hline Transit mode split, work trips (\%) & 1,146 & 25.3 & 14.1 & 0.0 & 68.2 \\
\hline Transit + walk + bike trips (\%) & 1,146 & 31.7 & 19.3 & 0.0 & 89.1 \\
\hline Pop density (persons per $\mathrm{km}^{2}$ ) & 1,151 & 5,564 & 6,428 & 0 & 82,434 \\
\hline Average pop density (persons per $\mathrm{km}^{2}$ ) & 1,151 & 5,975 & 4,457 & 20 & 30,527 \\
\hline Montreal & Obs. & Mean & Std. Dev. & Min & Max \\
\hline Transit mode split, work trips (\%) & 951 & 25.0 & 15.2 & 0.6 & 66.0 \\
\hline Transit + walk + bike trips (\%) & 951 & 34.3 & 22.1 & 1.3 & 94.3 \\
\hline Pop density (persons per $\mathrm{km}^{2}$ ) & 970 & 5,526 & 5,196 & 0 & 50,278 \\
\hline Average pop density (persons per $\mathrm{km}^{2}$ ) & 970 & 5,783 & 4,005 & 20 & 14,915 \\
\hline Vancouver & Obs. & Mean & Std. Dev. & Min & Max \\
\hline Transit mode split, work trips (\%) & 472 & 19.4 & 10.8 & 0.0 & 52.0 \\
\hline Transit + walk + bike trips (\%) & 472 & 28.0 & 16.7 & 0.0 & 78.3 \\
\hline Pop density (persons per $\mathrm{km}^{2}$ ) & 478 & 4,604 & 4,928 & 0 & 39,491 \\
\hline Average pop density (persons per $\mathrm{km}^{2}$ ) & 478 & 5,027 & 4,047 & 15 & 22,406 \\
\hline
\end{tabular}

after the breakpoint and hence the diminishing returns to density. The negative coefficients for $\beta_{2} s$ for Montreal (statistically insignificant) and Vancouver (statistically significant) suggest that at very high densities a shift from public transit to nonmotorized modes is likely.

The scatter plots in Figures 1A-C illustrate how the relationship between population density and transit mode split (illustrated with red regression lines) changes beyond the breakpoints, which are represented as black vertical lines with each dot representing a CT. At breakpoints, any further increase in density may not result in higher public transit mode share, although one may still observe an increase in public transit ridership.

Very high population densities in the three cities occur in and near downtowns, which are also major employment hubs resulting in both high population and employment densities. Because of mixed land uses, residents of very highdensity neighborhoods could walk or bike to work, as they benefit from shorter commutes. According to the 2016 Census, more than 90 percent of walk commutes between 8:00 and 8:59 a.m. in the three cities were less than $3 \mathrm{~km}$ long. One in two walking trips stretched for less than $1 \mathrm{~km}$.

This study tested the assumption that higher population densities in the three cities are characterized by mixed land uses. Thus, at higher densities, one would see an increase in the share of trips made by walking and biking.

The models reported in Table 3 regress the total share of trips by walking, biking, and transit (the sustainable modes) over average population densities. When the three modes are aggregated, the density breakpoints occur at higher densities. In Toronto, for instance, the breakpoint for sustainable mode share 
Table 2: Piecewise Regression Models of Transit Mode Split

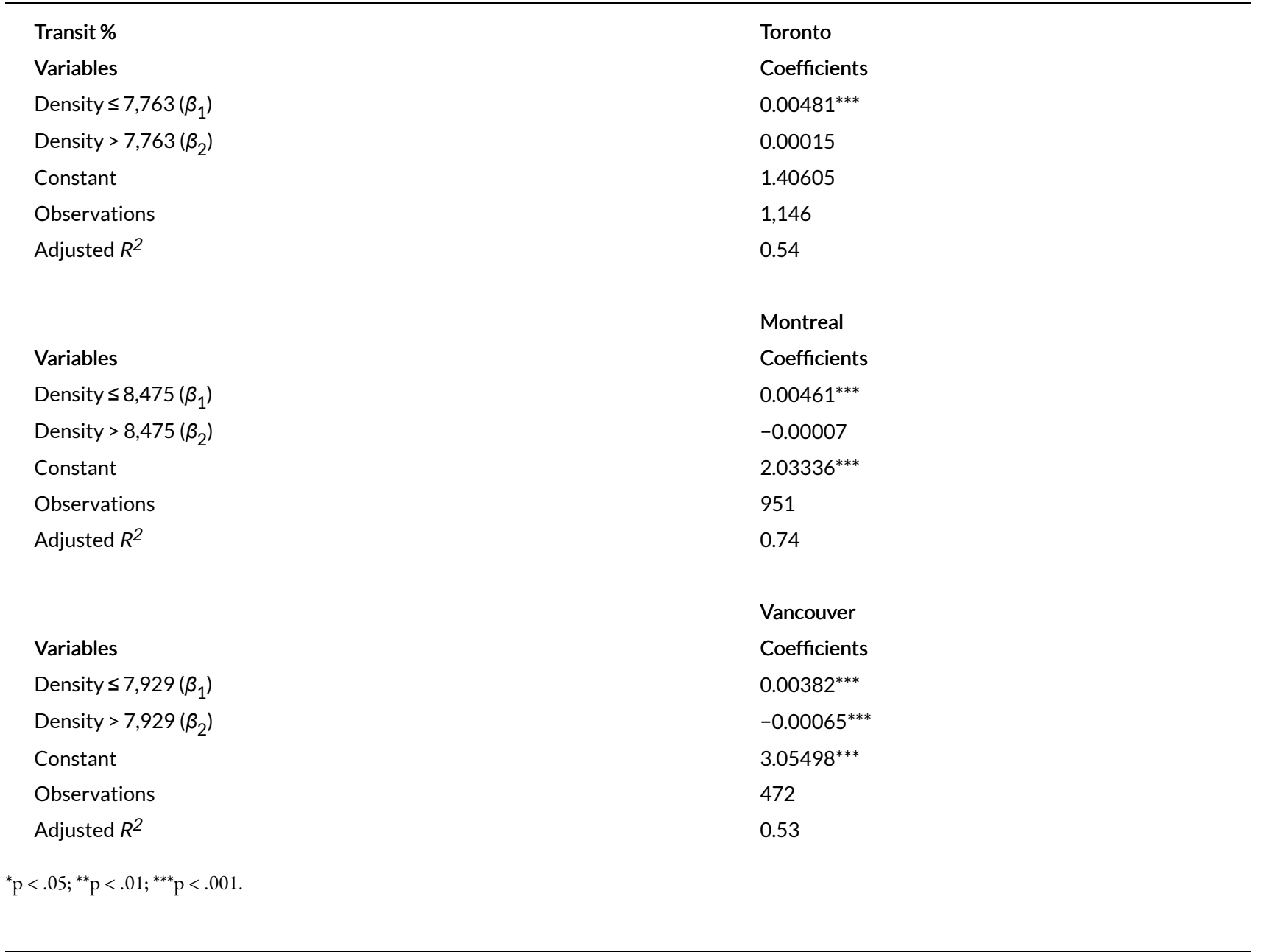

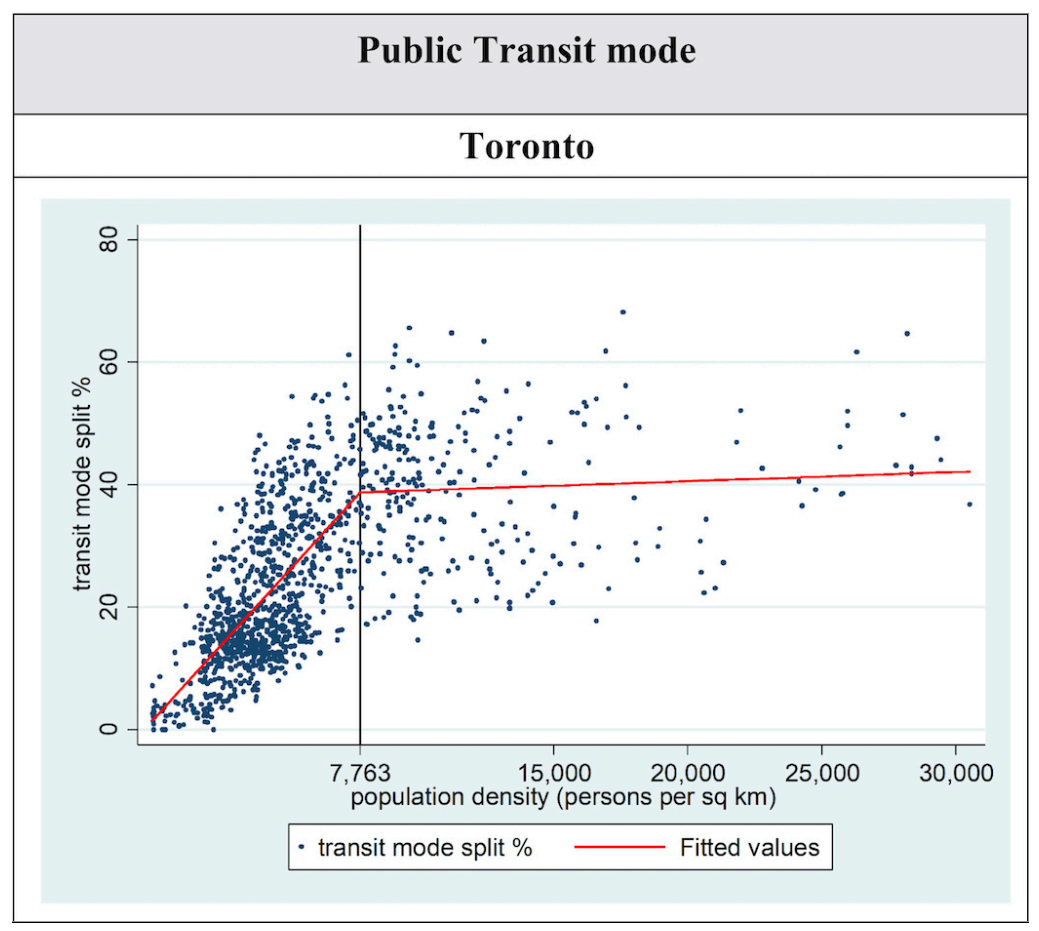

Figure 1A: Charting the Relationship between Population Density and Transit Mode Split 


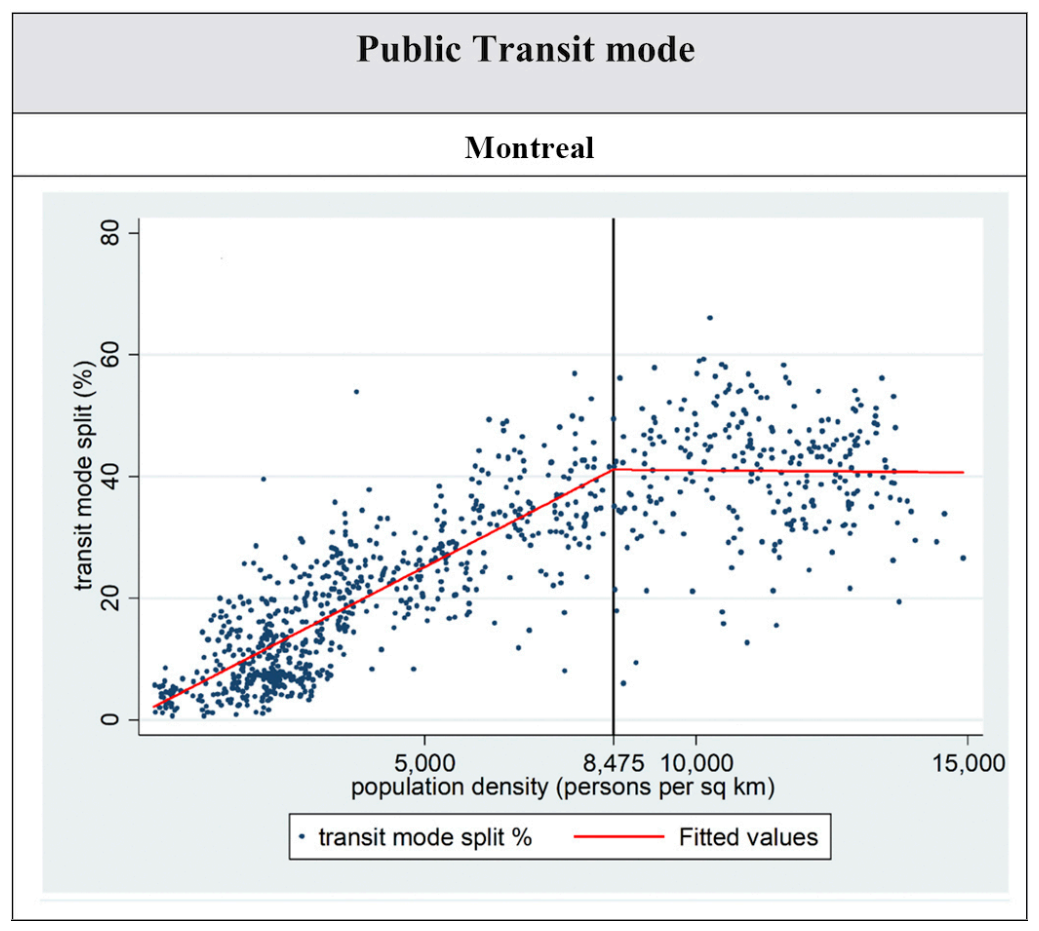

Figure 1B: Charting the Relationship between Population Density and Transit Mode Split

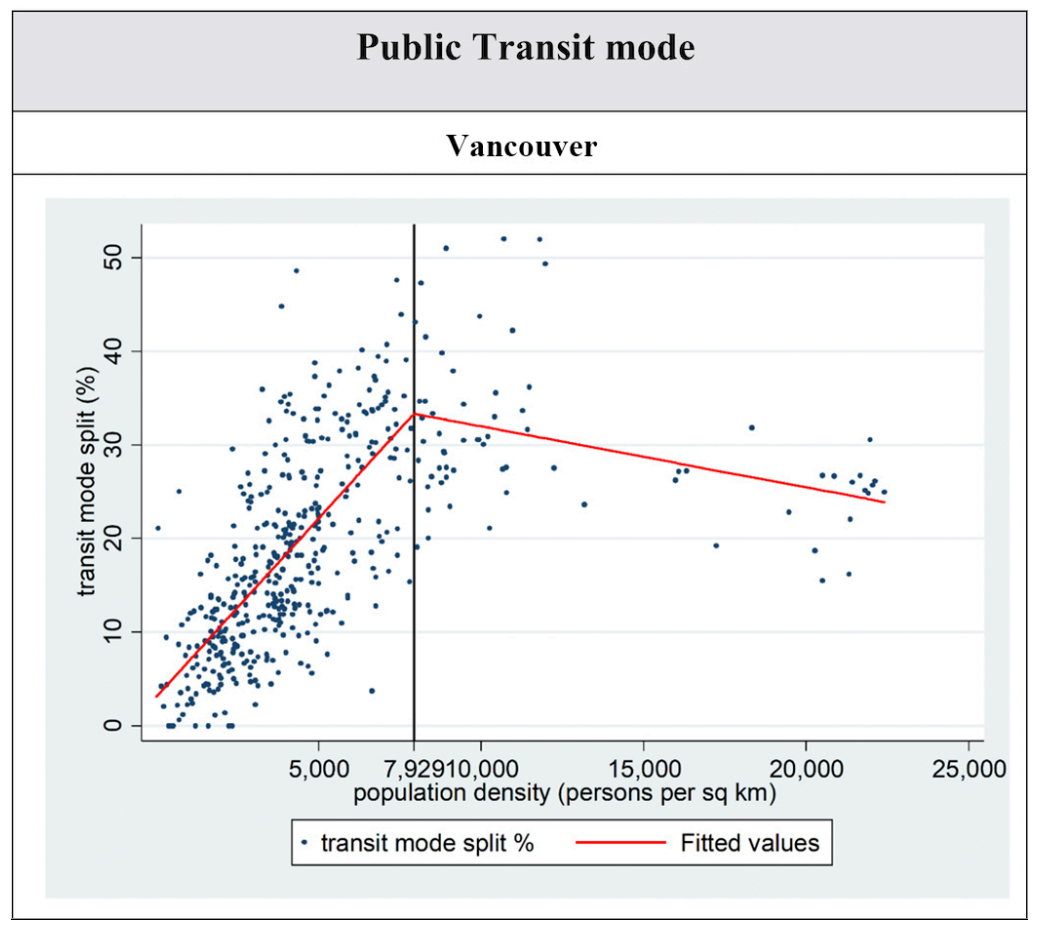

Figure 1C: Vancouver - Charting the Relationship between Population Density and Transit Mode Split

increases to 9,385 persons $/ \mathrm{km}^{2}$ from the 7,763 estimated earlier for transit mode share. This is illustrated in Figures 2A-C, where the new breakpoints are represented by solid vertical lines and those for transit mode split are represented by dashed vertical lines. 


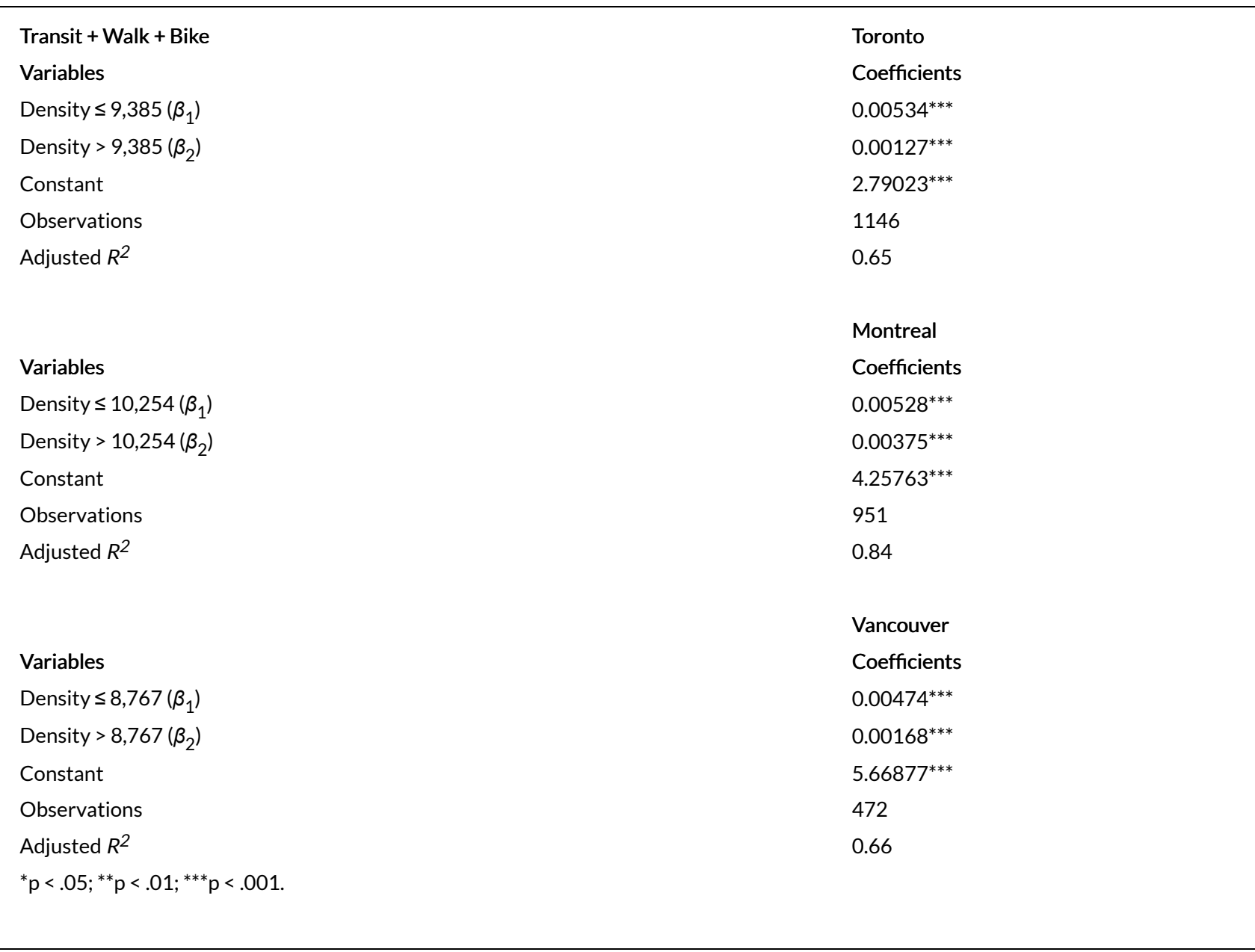

Interestingly, diminishing returns also hold for sustainable modes where the coefficients for slope after the breakpoint are smaller than those before the breakpoint, which we take as evidence for diminishing returns. The differences between respective slopes $\left(\beta_{1}-\beta_{2}\right)$ for the models reported in Tables 1 and 2 are statistically significant at $p<.05$.

Figures 3A-B illustrate that higher population densities in Toronto occur near subway stations and downtown (blue dots). Also, an increase in densities in CTs near subway stations and downtowns does not result in even higher transit mode splits. The correlation between the two variables is more pronounced for tracts located farther from subway stations and downtown. Thus, increasing population densities in suburban neighborhoods (red dots) and improving service by surface transit would help avoid the pitfalls of diminishing returns, which are more pronounced near transit stations and in the urban core.

\section{ACKNOWLEDGMENTS}

The author would like to express gratitude to Yemi Adediji, David Crowley, Liam Donaldson, Ahmed El-Geneidy, Bern Grush, Sumeet Gulati, and Stephen Wickens for their valuable feedback that has helped in improving the arguments advanced in this study. The author is grateful to anonymous referees for their suggestions. The author would also like to acknowledge the support 


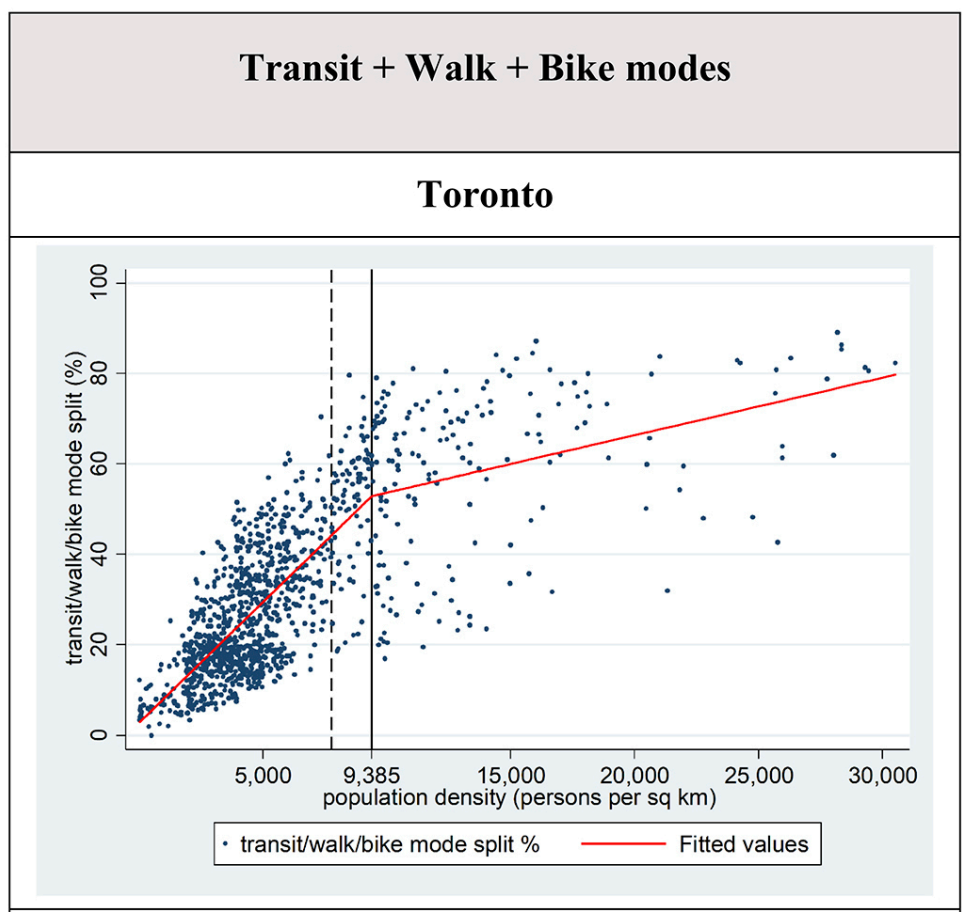

Figure 2A: Charting the Relationship between Population Density and Transit + Walk + Bike Mode Split in the Three Metropolitan Areas

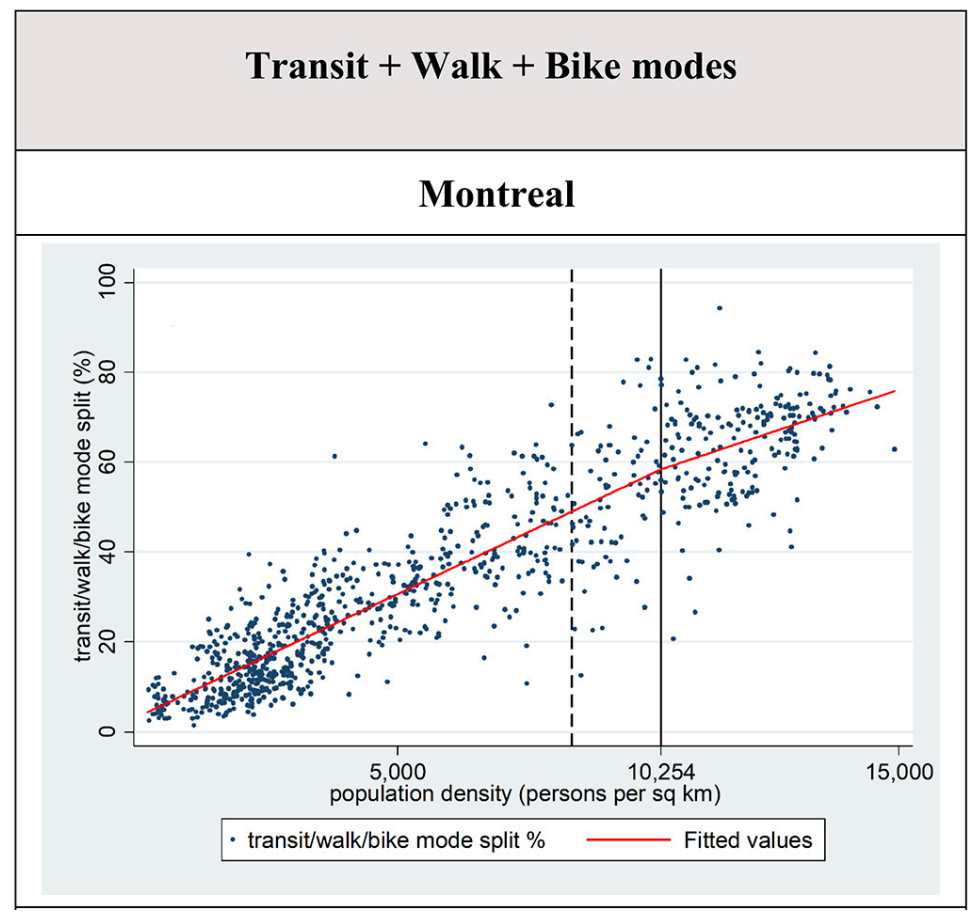

Figure 2B: Charting the Relationship between Population Density and Transit + Walk + Bike Mode Split in the Three Metropolitan Areas

of Caliper Corporation for providing the geocoded data for the 2016 Canadian population census. The nonlinear estimation routines were estimated in Stata with advice from Stata's support team. 


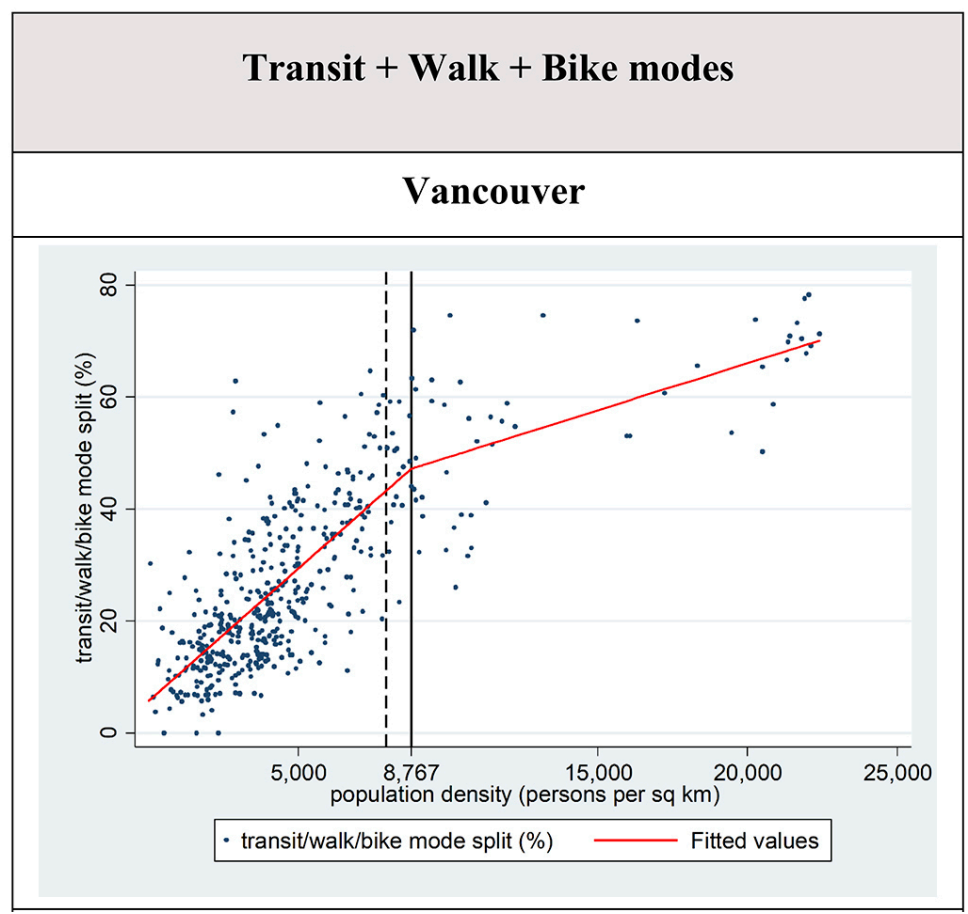

Figure 2C: Charting the Relationship between Population Density and Transit + Walk + Bike Mode Split in the Three Metropolitan Areas

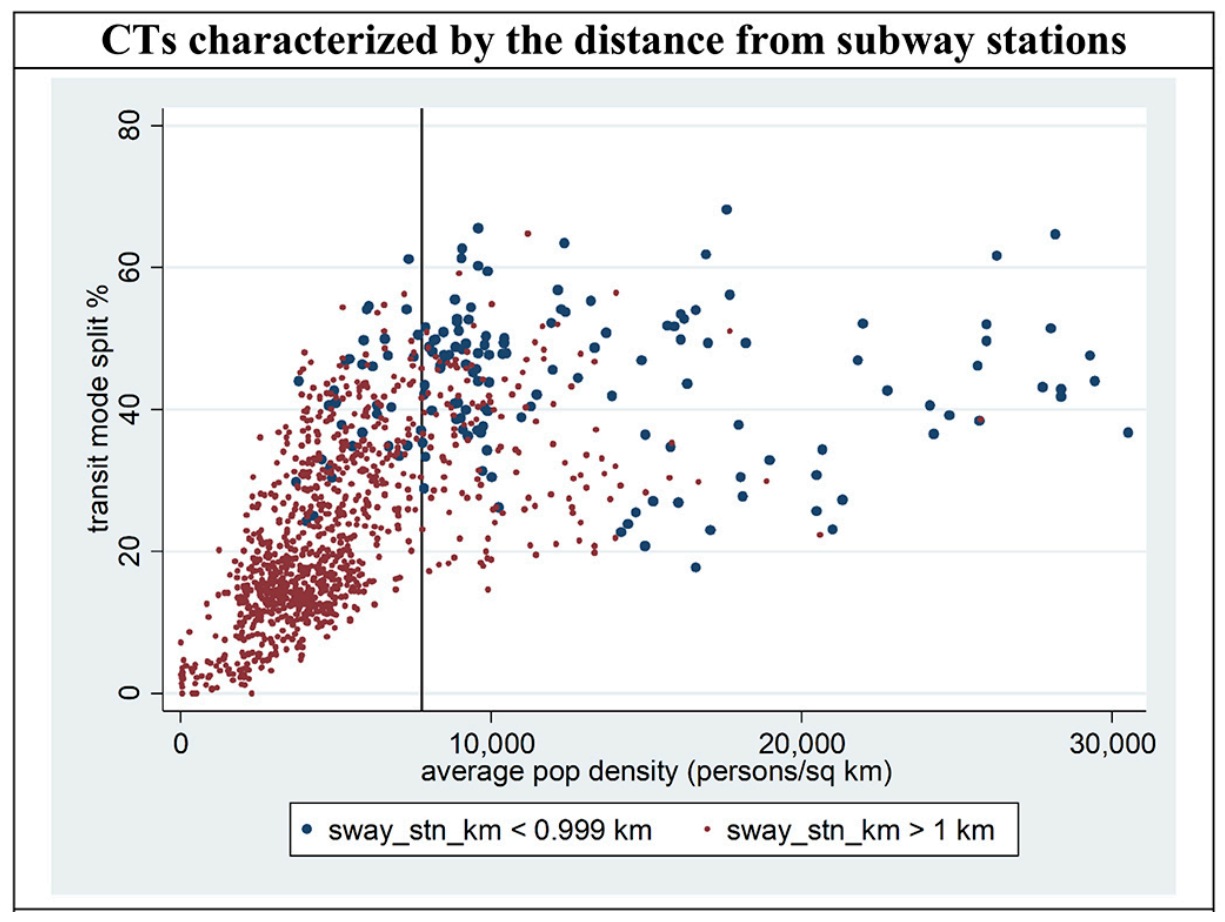

Figure 3A: Transit Mode Split and Proximity to Subway Stations and Downtown in Toronto

The author is solely responsible for all errors and omissions. 


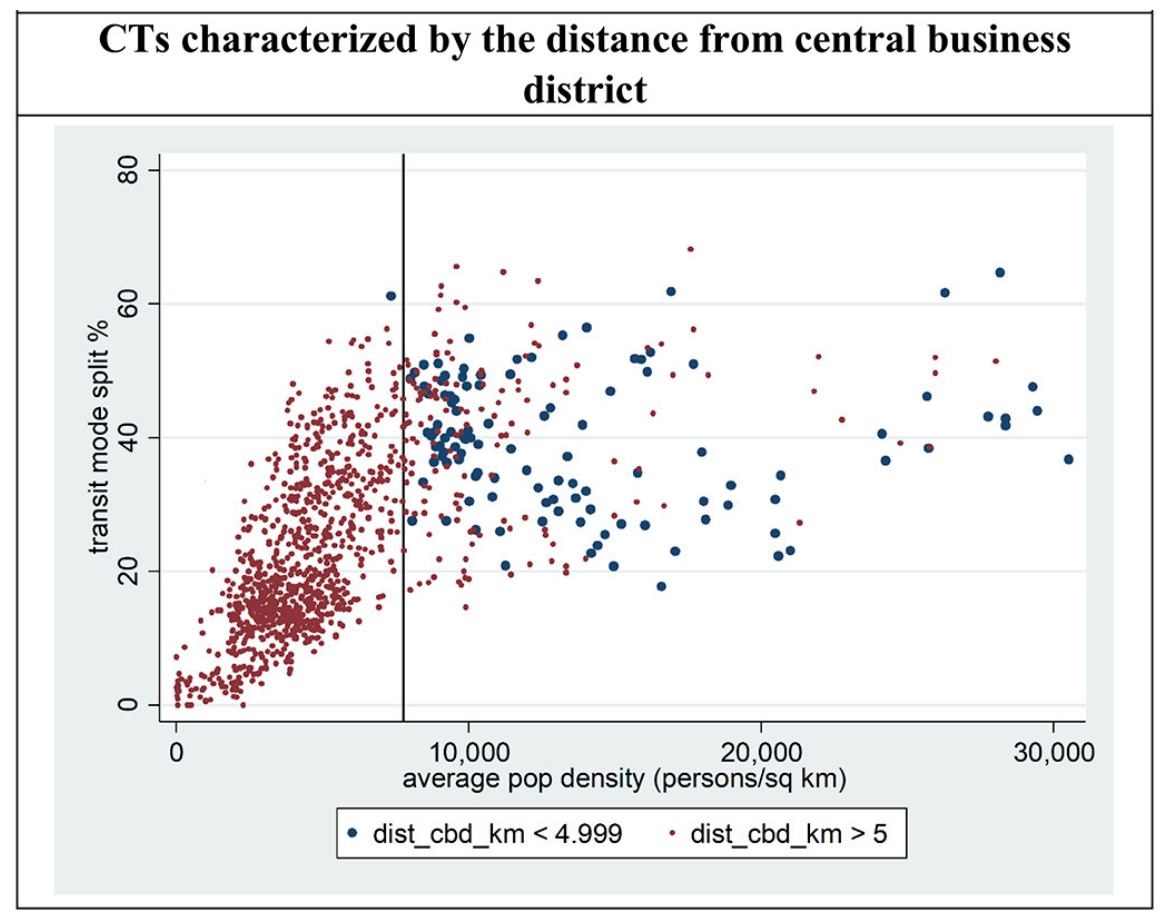

Figure 3B: Transit Mode Split and Proximity to Subway Stations and Downtown in Toronto 


\section{REFERENCES}

Cervero, R., and C. D. Kang. 2011. "Bus Rapid Transit Impacts on Land Uses and Land Values in Seoul, Korea.” Transport Policy 18 (1): 102-16. https://doi.org/10.1016/j.tranpol.2010.06.005.

Cervero, R., and K. Kockelman. 1997. "Travel Demand and the 3Ds: Density, Diversity, and Design." Transportation Research Part D: Transport and Environment 2 (3): 199-219. https://doi.org/10.1016/s1361-9209(97)00009-6.

Chakraborty, A., and S. Mishra. 2013. "Land Use and Transit Ridership Connections: Implications for State-Level Planning Agencies.” Land Use Policy 30 (1): 458-69. https://doi.org/10.1016/ j.landusepol.2012.04.017.

Ewing, R., S. Hamidi, G. Tian, D. Proffitt, S Tonin, and L. Fregolent. 2018. "Testing Newman and Kenworthy's Theory of Density and Automobile Dependence." Journal of Planning Education and Research 38 (2): 167-82. https://doi.org/10.1177/0739456x16688767.

Government of Ontario. 2017. "Places to Grow: Growth Plan for the Greater Golden Horseshoe, 2017." http://www.placestogrow.ca/ index.php?option=com_content\&task=view\&id=430\&lang=eng.

Mankiw, N.G. 2014. Principles of Economics. 7th ed. Stamford, CT: Cengage Learning.

Mitchell, M.N. 2012. Interpreting and Visualizing Regression Models Using Stata. College Station, TX: Stata Press. https://www.surveydesign.com.au/preview/ivrm-preview.pdf.

Næss, P. 2015. "Built Environment, Causality and Travel." Transport Reviews 35 (3): 275-91. https://doi.org/10.1080/01441647.2015.1017751.

Newman, P. W. G., and J. R. Kenworthy. 1991. "Transport and Urban Form in Thirty - two of the World's Principal Cities." Transport Reviews 11 (3): 249-72. https://doi.org/10.1080/ $\underline{01441649108716787 .}$

Polzin, S. E., X. Chu, and J. R. Rey. 2000. "Density and Captivity in Public Transit Success: Observations from the 1995 Nationwide Personal Transportation Study." Transportation Research Record: Journal of the Transportation Research Board 1735 (1): 10-18. https://doi.org/10.3141/ 1735-02.

Statistics Canada. 2012a. “Census Tract: Detailed Definition.” https://www150.statcan.gc.ca/n1/ pub/92-195-x/2011001/geo/ct-sr/def-eng.htm.

- - . 2012b. “CMA and CA: Detailed Definition.” https://www150.statcan.gc.ca/n1/pub/ 92-195-x/2011001/geo/cma-rmr/def-eng.htm.

- - . 2017. "Focus on Geography Series, 2016 Census: Census Metropolitan Area of Toronto." https://www12.statcan.gc.ca/census-recensement/2016/as-sa/fogs-spg/Facts-cmaeng.cfm? $L A N G=$ Eng\&GK=CMA\&GC $=535 \& T O P I C=1$.

Zhang, M., and N. Kukadia. 2005. "Metrics of Urban Form and the Modifiable Areal Unit Problem." Transportation Research Record:Journal of the Transportation Research Board 1902 (1): 71-79. https://doi.org/10.1177/0361198105190200109. 